\title{
Steel cleanliness and environmental metallurgy
}

\author{
Jean-Pierre Birat ${ }^{1,2}$ \\ 1 ESTEP, Belgium \\ 2 IF Steelman, France \\ e-mail: jean-pierre.birat@ifsteelman.eu
}

\section{Key words:}

Metallurgy; non-metallic inclusion cleanliness; environment; cleanliness of air emissions; environmental metallurgy

\begin{abstract}
Clean steels were "invented" in the middle of the 20th century, at a time when steels started to be produced en masse and when it was understood that quality should also be addressed as a special and important issue, both in terms of the strategy of the sector and as a major research topic for the science and technology that accompanies the industry. The series of Clean Steel conferences, launched in Hungary in 1970 and organized every 4 years since then, with Paul Tardy in the organizing committee or in the lead, have been providing important time markers of this evolution. Since then, major progress was made by the introduction in most steel shops of secondary or ladle metallurgy, which was invented in the process, while steel cleanliness was defined precisely in standards and textbooks. The discoveries of pioneers have become state-of-the art and, today, a steady state situation has been reached, where research continues in using new tools and methods to refine the topic, while new comers, mainly from the BRIC countries, are contributing their understanding of the topic to the international steel community. The distinction between special steels and carbon steels got blurred in this historical process, as similar secondary metallurgy tools were used for making both kinds of steels and, in essence, steel ceased to be a simple commodity and most steels became special to some extend. Clean steels have thus not become much more sophisticated recently, but rather much more common and mainstream. The expression "clean steel" stems from a vision of the purity of the metal in terms of minor elements, which had been controlled until then only at the margin compared to the major elements, iron, carbon, silicon and manganese. This is today a somewhat passéed vision as metallurgy has become a much more holistic and systemic technology, whereby steels are defined in terms of global composition, of distribution of phases, including the minor phases that are known as non-metallic inclusions, of microstructures and, more often than not, in terms of applications and properties in service. Moreover, steels have time extensions, which are discussed as life cycle or value chain and are thus embedded in the anthroposphere and its intersection with the biosphere and the geosphere. This emphasizes the fact that steels are made from raw materials, primary and secondary - thus including scrap from recycling -, that they are transformed into artifacts that participate to the life of society and eventually are disposed of at end of life to feed back into the circular economy. This holistic vision is what we call "environmental metallurgy". It is linked to clean steel production and constitutes another dimension of the cleanliness of steel.

Plenary presentation to the 9th International Conference on Clean Steel; 8-10 September 2015; Budapest; Hungary
\end{abstract}

Received 22 September 2015 Accepted 7 December 2015 of the settlers who had replaced the huntersgatherers of the Mesolithic [3], it turned into a structural material, used to give shape, strength, elasticity, toughness and eventually engineering audacity to the exploding number of small and large artifacts designed and produced by humankind around the time of the industrial revolution. What is truly remarkable is that this trend has been continuing across centuries and that production has been multiplied almost one hundred times since the beginning of the 20th century. The robustness of steel to serve as 


\section{Acronyms}

\begin{tabular}{|ll|}
\hline AOD & Argon Oxygen Decarburization \\
AS & Anthropospheric Services \\
BES & Biodiversity and Ecosystem Services \\
BF & Blast Furnace \\
BFG & BF Gas \\
BOF & Basic Oxygen Furnace \\
BOG & BOF gas \\
CAS-OB & Composition Adjustment by Sealed \\
& argon bubbling with Oxygen blowing \\
CC & Continuous Casting \\
CCC & Centrifugal Continuous Casting \\
CCS & Carbon Capture And Storage \\
CFD & Computer Fluids Dynamics \\
COG & Coke Oven Gas \\
DH & Dortmund-Horder process \\
EC & European Commission \\
EP & European Parliament \\
EU & European Union \\
LCAK & Low-carbon, aluminum killed steel \\
LIBS & Laser Induced Breakdown \\
& Spectroscopy \\
MIDAS & Mannesmann Inclusion \\
& Detection by Analysis Surfboards \\
NMI & Non-Metallic Inclusion \\
PAH & PolyAromatic Hydrocarbons \\
PM & Particulate Matter \\
POC & Persistent Organic Compound \\
RH & Ruhrstahl Heraeus process \\
RH-OB & RH with Oxygen Blowing \\
S/LM & Secondary/ladle metallurgy \\
SAM & Society and Materials \\
SEV & Statistics of Extreme values \\
SOVAMAT & SOcial VAlue of MATerials \\
TEEB & The Economics of Ecosystems \\
& and Biodiversity \\
TRL & Technology Readiness Level \\
TSC & Thin Slab Casting \\
ULCOS & Ultra-Low CO Steelmaking \\
ULCOS-BF & Ultra-Low CO 2 \\
UNFCC & Steelmaking Blast Furnace \\
VOD & United Nations Framework \\
& convention on Climate Change \\
& Volatile Organic Compound \\
& \\
& Vacuum Oxygen Decarburization \\
\hline
\end{tabular}

a core structural material of society and a key part of its evolving technological epistemes has been constantly at work in these changing times of demographic and economic explosion.

Other materials, like wood and concrete, demonstrate similar features, but only steel exhibits such universality.

This role of steel is bound to continue in the future and the only questions open are the exact years when production level passes the 2 billion ton threshold and then the 3 billion one [4].

Iron and steel went through many transformations during this long historical process and their properties, as well as the technologies used for making them, have transformed congruently by several orders of magnitude. If steel is an invariant of the technological epistemes of society, it is because of its plasticity to adapt to changing times and changing needs. This is what is called today in European Commission (EC) speech a Key Enabling Technology (KET) advanced materials are the relevant KET, which introduces the idea that new materials are being invented continuously but also that existing ones are being refined, reformulated and changed just as continuously. A former expression used by the EC was that of cumulative technologies, thus emphasizing that materials like steel demonstrate a pawl and ratchet effect, where features accumulate and do not vanish, as they would in a marketing product of limited life.

In a holistic vision, steel partakes of the anthroposphere $^{1}$ and of the biogeosphere and it circulates between both: it is thus not simply part of the anthroposphere or of the technosphere. In simpler economic terms, the matter is the circular economy, of which the EC is fond nowadays. Steel is used to mark frontiers, separations between artifacts, society and nature [5] (cf. further, "Societal challenges and steel anthropospheric services").

Steel originates from earths concentrated into usable ores, from energy resources and from reducing agents and other fluxes, all from the geosphere, and it enters the technosphere to become metallic and alloyed, while the "gangue" is separated out of the major element, iron, to become a by-product, solid (slag dust, mill scale, etc.), gaseous (e.g. COG, BOG, BFG, etc.), sometimes liquid (pickling solution, etc.) or mixtures of these

\footnotetext{
1 The anthroposphere is the physical, symbolic and cultural part of the planet, where mankind lives and which it has transformed to create its habitats through arts, crafts and technology. It is also called society or technosphere. The expression originates from scientific ecology and geography. Many disciplines, like most of the social sciences, are interested in the anthroposphere and thus use different words to refer to it.
} 
(e.g. sludge, oily scales). While steel moves further into becoming a material embedded in artifacts, which are used for short or long lives and then eventually get discarded, the byproducts are either used in other sectors in an industrial ecology synergy or landfilled. All may be dissipated to the environment to a small extent.

Steel itself can be reused or recycled and, indeed, steel is the most recycled material [6]. The complexity of this scheme is obvious but is compounded by the fact that steel is not simply iron, but contains other elements, either originating from the initial raw materials, or added as alloying and similar elements. These have a different fate in the recycling loop from iron's: some are also recycled, often co-recycled with iron, while others are simply lost.

Steel is thus not simply identical to element iron, even if carbon steel is one of the simplest alloys in metallurgy. Steel is a complex mixture of elements, a complex alloy and a complex set of phases, depending on temperature and kinetics histories.

Why have minority elements and tertiary phases been ignored initially, when metallurgy developed the power to explain how metals function, and were given ancillary names like trace elements, tramp elements, non-metallic inclusions (NMI) and precipitates, like an afterthought?

On the one hand, because steel's microstructure and properties could be explained only in terms of the major chemical elements in its composition, i.e. iron, carbon and possibly silicon and manganese as well, even phosphorous and sulfur, which is a tribute to the synthetizing and unifying strength of scientific theories - a kind of application in a different realm of the Pareto principle and of the universality, in simple physics, of the linearity between causes and effects $^{2,3}$.

On the other hand, the human mind has a finite number of categories and models according to which to organize thought and

\footnotetext{
${ }^{2}$ It also makes it possible to teach metallurgy in a simple way, like physics or chemistry are taught. So much for the Professors!

3 Non-linearities are often initially handled by perturbation theory, as if the complexity of nature was perturbing the simple beauty of the construct of basic theory.
}

knowledge [7] and the concepts of purity and cleanliness (or cleanness) were powerful and available to acknowledge the gap between reality and the simple models that science proposes.

Steel is mainly a binary alloy of iron and carbon, but many more elements are part of its composition. Some remain as a memory of the raw materials and reactants used in the iron and steelmaking processes while some more have been added voluntarily, since it was understood in the Neolithic that properties could be changed greatly by adding some small amounts of alloying elements ${ }^{4}$. The detailed composition of a steel serves as a record of the history of the metal.

Another conceptual dimension is related to how useful or perturbing the minor components are: the minor elements/components that bring positive value, or usefulness to steel have been given specially positive names, like alloying elements, additions, precipitates or, more recently, nano-features. Those that bring negative value are given negative names, like tramp elements, inclusions and non-metallic inclusions ${ }^{5}$, impurities, third phases, slag particles, etc.

Note further that the value is relative to the steel itself, its properties and applications. The more holistic dimension of steel, in terms of temporality and of context, is ignored at that stage, which corresponds to the state of knowledge of the middle of the 20th century. The impact on resources, air, water and soil quality, health of workers and population, or its general societal role are ignored in this narrow, one-dimensional definition of steel.

Purity in metallurgy relates to chemical composition and on to how close that composition is from that of a model metal, which would contain only the core, basic and "useful" elements. Cleanliness relates to phases with an ideal of no ternary phases at all. One concept does not necessarily lead to the other, in this case cleanliness to purity, like it does in the philosophy of the

\footnotetext{
4 Even if this does not contradict the linearity "principle", the amount of effect of a small addition can be very large!

5 As if referring to a mineral, i.e. a non-metal, was being even more derogatory!
} 
Ancient Greeks, of Nietzsche or in the major religions, although purity and cleanliness in metallurgy separate reality from the beauty of the model metal taught in university classes and born of theory, thus of the human mind. Thus the three words of Nietzsche's quote, cleanliness, purity and beauty, are relevant in this area as well!

Note also that this dichotomic view of metals does not help understand why some elements, like chromium, nickel or cobalt, are sometimes called tramp elements while in other cases there are termed additions or alloying elements. It does not help understand either how inclusions and precipitates may cooperate or why the distinction between them gets blurred, like in oxide metallurgy $[8,9]$.

A more holistic view is necessary today to reach beyond the distinction between majority and minority phenomena, between inside and outside of steel ${ }^{6}$. It is probably necessary to implement a paradigm shift that would acknowledge the complexity of the connection between anthroposphere and bio-geosphere and to address it directly.

Cleanliness, the subject matter of this paper and of this conference cleanliness, should therefore be seen as a remnant of the history of science and technology rather than a proper, up-to-date account of a metallurgical issue. The deconstruction of concepts long taken for granted in the past is common nowadays in many areas of social sciences, for example in history, anthropology, archeology and prehistory [2]: metallurgy should now follow suit.

\section{Historical construction of the concept of clean steels}

Reviewing the construction of the concept of clean steels sheds light on the concept of modern materials.

\footnotetext{
6 The papers published in this conference that originate from emerging economies, where the culture is based on non-European paradigms, may eventually help implement this shift. As they are the most numerous, this may happen fast!
}

\subsection{Historical narrative}

When iron and steel emerged in history ${ }^{7}$, the metal was reduced in the solid phase in a bloomery: thus the iron bloom was a mixture of reduced iron ${ }^{8}$ and of the gangue of the ore, a true composite material. The gangue was removed by forging the bloom to expel the mineral elements out of the metal. The outcome was an iron very different from today's steel: for example, the amount of minerals in samples from the late Iron Age (La Tène final) was between 10 and $\%$ in volume, the latter being considered as a clean piece of material [10]: in terms of total oxygen content, the spread was thus roughly between 14000 and 200 ppm. Nobody talked explicitly about cleanliness then, although the quality issues that were raised (early fracture) were probably understood by the smiths of that time.

The evolution towards modern steelmaking, i.e. to an all-through liquid production from hot metal to liquid steel (Bessemer and Martin-Siemens processes), has changed the picture in terms of cleanliness very significantly. The production of liquid hot metal in the early blast furnaces eliminated gangue inclusions, the liquid gangue being separated by density: however, new inclusions of a different kind, due to oxidation, were introduced during subsequent forging, a completely new genesis of these ternary phases. Most of these were eliminated when liquid steel was produced as crucible steel or puddled iron but new kinds of inclusions were created, due to reoxidation of liquid steel along with contamination by refractory and liquid mineral phases

\footnotetext{
7 The first reduction of iron ore into iron metal is attributed to the Hittites in Asia Minor at the end of the 3rd millennium, i.e. before the onset of the Bronze Age (1600). Then the metal moves west to Europe and the first artifact made of iron are from the 17th century. Then, in the 8th century, it became fairly widespread from Greece to Scotland, as a series of prestige artifacts, including swords (the famous Halstatt words), owned by the aristocracy of the chiefdoms. Their functions as weapons may have been secondary to their role as a marker of power. Only by the 3rd century was it incorporated into peasants' tools and was widely used by society at large [2].

${ }^{8}$ Plus some steel and possibly some pig iron as well...
} 
(slags). Studies picturing this historical evolution in a quantitative way, i.e. a timeevolution of cleanliness, measured for example by total oxygen content, are lacking.

The concept of cleanliness was born initially from the observation under the optical microscope of non-metallic inclusions by the newborn discipline of metallography.

Cleanliness was rated against standard images of microscopic fields, where geometry (shape and size) and distribution of non-metallic inclusions was distinguished against various image types [11]. The trained observer had established that some shapes were acceptable in some steel grades and that smaller inclusions generally were more acceptable than larger ones. Although the composition of inclusions was not available by then, the observer had established a correspondence between grades and inclusion composition by families (sulfides, silicates, aluminates, alumina, composite inclusions) based on the sulfur content and deoxidation history of the steel. These methods, developed in the 20th century and standardized after the 2nd World War, preempted the general use of continuous casting and of ladle metallurgy, and therefore were invented in a process technology context fairly different from today's.

The further development of the concept of cleanliness went on by exploring various issues in parallel, based on laboratory work, basic research into the physical chemistry of steelmaking, steelshop experimentation, development of new process reactors and new, innovative solutions to control inclusions composition, shape, size and distribution to be eventually introduced in the routines of steelmaking practice.

\subsection{A modern vision of cleanliness}

A modern vision of cleanliness has emerged from this 30-40 year concept-building effort $[8,12]$.

Inclusions constitute a cloud of phases dispersed in the metal matrix and defined by a multi-dimensional set of parameters, including composition, shape, size and distribution. This full description is not readily available and one of the main issues related to assessing cleanliness is to observe representative samples to estimate these parameters with a reasonable accuracy and representativity: one difficulty is related to large inclusions (e.g. $100 \mu \mathrm{m}$ or more), which are extremely rare and therefore difficult to see, unless very large-size samples are analyzed.

Another issue is due to the fact that the NMI population depends on time (in the process timeline of the steel shop) and on temperature. Thus a ladle sample, collected and analyzed with care and finesse, may give a reasonably good estimate of the cleanliness there and then, but it may bear almost no connection, whatsoever, with the cleanliness of solid steel. There is thus a huge amount of literature devoted to discussing when a representative sample of liquid steel ought to be taken in order to assess both steel composition and NMI cleanliness [13].

\subsection{Elements, purity and thermodynamic equilibriums}

The chemical elements initially involved in cleanliness are mostly the non-metals of the Mendeleev table, because they exhibit higher solubility in liquid steel than in the solid: thus carbon, nitrogen, oxygen, phosphorous, sulfur, selenium and hydrogen. To this list, one can add metalloid neighbors in the table, like boron, arsenic, antimony and tellurium. Some of these elements originate from primary raw materials $(\mathrm{P}, \mathrm{S}, \mathrm{As}, \mathrm{Sb})$ or from ironmaking $(\mathrm{C})$, while most of the others are due either to contamination by the atmosphere $(\mathrm{O}, \mathrm{N}, \mathrm{H})$, to the general oxidizing practice $(\mathrm{O})$ used in steelmaking, to the electric arc in the EAF (N) or are voluntarily added (C, Se, Te, B). Recycling and circular economy practices, in place or to come, (will) bring in some of these elements in different ways (e.g. Sb from red mud, if it were used as an iron ore substitute). Pollution by tramp elements (metals like copper, tin, chromium, etc.), related to the use of scrap, is usually not considered as a cleanliness issue.

Phosphorous and sulfur levels are usually handled prior to the steel shop, first by selecting the raw materials and then by controlling $\mathrm{P}$ and $\mathrm{S}$ levels in hot metal (desulfurization, more rarely dephosphorization of hot metal) or during oxygen steelmaking 
(dephosphorization in the converter). Further control on steel is always possible, but only necessary for some high-end specific grades (e.g. slag desulfurization in ladle metallurgy, whenever $S<10 \mathrm{ppm}$ ) [14].

At the end of steelmaking in the BOF or the EAF, oxygen is at equilibrium with carbon, which means very high levels for low carbon grades (1250 ppm oxygen for $0.02 \%$ carbon). If steel would simply solidify as such, eutectics of iron, sulfur and oxygen would precipitate in the interdendritics, while a strong carbon deoxidation would take place in the initial stages of solidification, thus producing rimming steels, full of blowholes near the surface. The resulting metal in addition to being porous, would be brittle during hot forging and subsequent use at room temperature (rouverain iron). To avoid precipitating oxygen and sulfur iron eutectics, deoxidation agents (carbon, especially under reduced pressure, manganese, silicon, aluminum, calcium, titanium, etc.) and desulfurizing agents (manganese, calcium) are introduced into the system in order to promote new equilibriums whereby third phases precipitate and rimming is avoided altogether ${ }^{9}$. The third phases constitute the endogenous NMIs (oxides, nitrides, carbides, sulfides, phosphorides, etc.) that are initially created in liquid steel, usually in the ladle [15].

These equilibriums can be implemented by adding deoxidants into liquid steel by bulk additions or wire injection or by ensuring that the liquid metal is in equilibrium with an active metallurgical slag of the proper composition.

The NMI population changes all the time, because existing inclusions coalesce, float out and get finally adsorbed in a slag or a simple covering powder or flux, by aggregation against refractory in the ladle, the tundish or inside nozzles that some of them (solid NMI, like alumina or spinels) tend to clog. Steel and slag change as well, and inclusions entertain complex connection with them, at equilibrium, if time allows, or out of it. More inclusions appear, because

${ }^{9}$ Gas evolution at the solidification front can still take place if nitrogen and hydrogen are not properly controlled. temperature drops ${ }^{10}$, which usually means more precipitation, or solidification starts, or oxygen penetrates the system (reoxidation), from the slag, the refractories, from the atmosphere at refractory junctions (sliding gates, submerged nozzle mounting, across the refractories, etc. $)^{11}$, or because the slag or the refractories generate new inclusions or release inclusions previously captured. The latter fall under the name of exogenous NMIs. Of course, the trend is usually towards improved cleanliness and research has been looking deeply at all these mechanisms, at modeling them by simulation with more and more sophisticated mathematical modeling (CFD) and at proposing countermeasures based on this insight.

A comparison of the various mechanisms of inclusion elimination taking place in the ladle is shown in Figure 1, which was produced by computer CFD simulations [16].

An important point regarding reoxidation is that the phenomenon does not take place at thermodynamic equilibrium, but rather generates oxides of whichever element happens to meet the incoming oxygen, most often generating iron oxides. Out of equilibrium in deoxidized liquid steel, they will later reverse back to equilibrium NMI, if time allows.

The distinction between endo- and exogenous NMI is however somewhat ad hoc, as deoxidation or reoxidation are actually an integral parts of the total system of steelmaking and both result from the technology put in place to produce steel: for example, deoxidation does not take place inside liquid steel, but at the interface of the deoxidant injected, for example, as a wire into the ladle and thus the resulting NMIs do not quite deserve to be called endogenous.

NMI inclusions are large enough to interact with the metal matrix as mechanical discontinuities, basically like holes. There are other third phases in steel of much smaller dimensions called precipitates, which

\footnotetext{
${ }^{10}$ A drop in temperature of $100{ }^{\circ} \mathrm{C}$ cuts dissolved oxygen level by half.

11 Direct contact with the atmosphere is usually completely avoided, nowadays, except in the case of billet open stream casting, of centrifugal continuous casting and of ingot casting, because of surface fluxes and powders and of refractory nozzles, mostly submerged.
} 


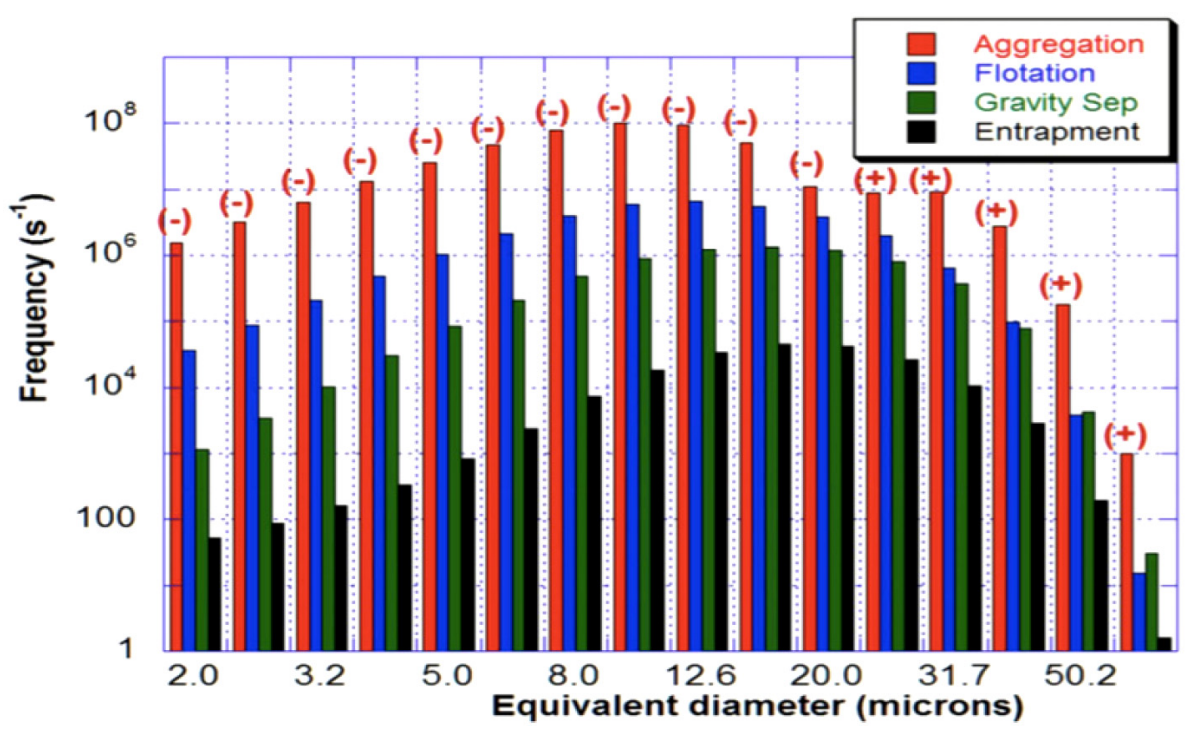

Fig. 1. Simulation of the mechanisms of elimination of NMI in a ladle furnace. The initial distribution is a log-normal one, with $0.176 \mathrm{~kg} / \mathrm{m}$ of calcium aluminates corresponding to $7.9 \mathrm{ppm}$ of total oxygen [16].

interact with the matrix as the scale of dislocations or even at atomic scale (GP zones $^{12}$ [17]). Precipitates, usually carbides or nitrides, constitute the key features of micro-alloying as in HSLA steels (driven by niobium, titanium, vanadium, aluminum, but also copper) or of more substantial alloying like in tool steels or in sophisticated stainless steels. They provide precipitation hardening. They are not within the scope of the present paper. Structures like GP zones or perlite are some of the first nano-structures identified in material science.

The many phases that can impersonate iron (ferrite, perlite, bainite, residual austenite, martensite and their infinite variants) are not part of the present discussion of cleanliness either, as they lie at the very core of steel metallurgy, i.e. of the physics of "pure steel". They are controlled by static or thermomechanical heat treatment. Grain boundaries, which are not phases by themselves, are also part of this metallurgy universe.

There is a porous interface between NMI and precipitates, of which oxide metallurgy gives a good example. The concept is to use

\footnotetext{
12 "a first example of a structure which is found in many oversaturated solid solutions in the course of their returning to stable equilibrium", A. Guinier, Personal reminiscence.
}

inclusions to promote ferrite nucleation in carbon steels, at the $\alpha \rightarrow \gamma$ transformation interface, to foster fine grain size [8]. For example titanium oxides, coated by manganese sulfides, have been used for that purpose in weldable plate grades. This exhibits a synergy between NMIs and precipitates, and demonstrates that a continuum connects the two categories of third phases.

The focus here has been on oxygen elimination or on avoiding oxygen contamination. A similar discussion should address nitrogen and hydrogen as well, but it will not be exposed here (see for example [18]). The same comment is valid for sulfur (e.g. a common rule is for manganese to be present in excess of sulfur in order to favor precipitation of MnS inclusions: $\% \mathrm{Mn}>40 \% \mathrm{~S}$ ).

\subsection{Process tools for cleanliness control}

The construction of the concept of cleanliness took place in parallel with the development of new specific tools in the steel shop, thus new process reactors and technologies which are widely used today to control cleanliness and have redefined the field.

This transformation has been progressive. 

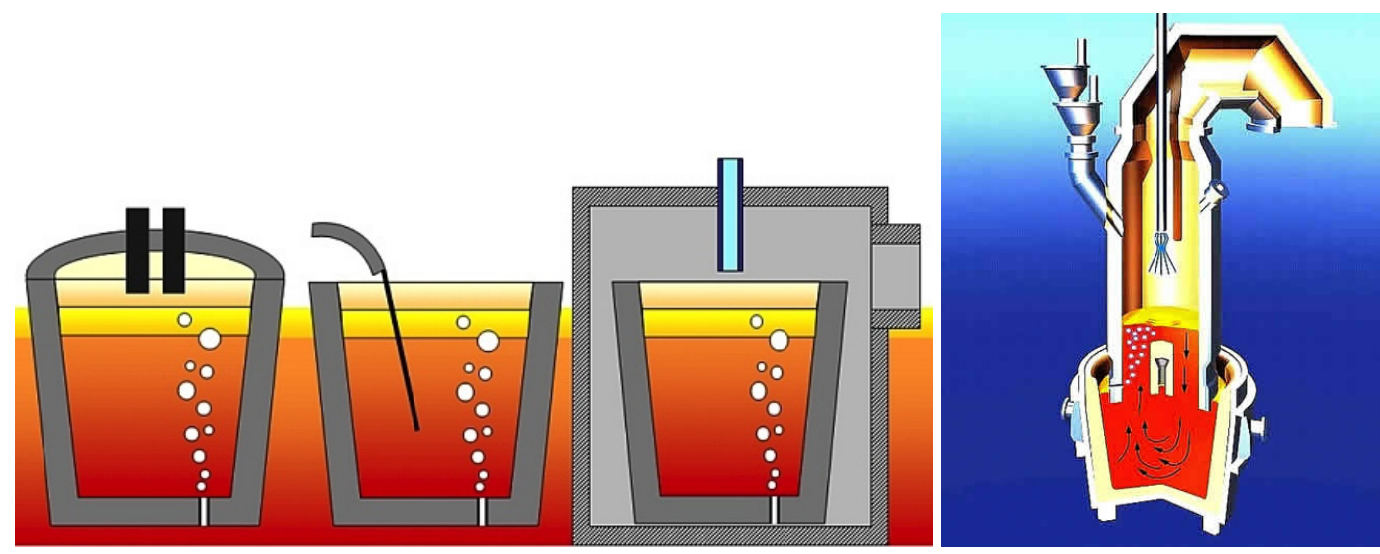

Fig. 2. ladle furnace with argon bubbling, cored-wire injection with argon bubbling, tank degasing; RH.

It started from the production of engineering steels for the automotive, power and aircraft sectors with the purpose of increasing the reliability and life of the mechanical parts of vehicles or nuclear reactors. The major need, hic et nunc, was to control the hydrogen level in liquid steel (to less than $1 \mathrm{ppm}$ in a carbon steel) in order to avoid its departure at solidification and its entrapment in the solid, which leads to serious integrity defects during the use of the metal part. The use of vacuum, which removes hydrogen straightforwardly, was proposed and generalized in these steel shops, using various technologies like tank degasing, stream degasing, DH or RH. It was also understood that vacuum treatment allowed for other benefits, like carbon deoxidation, which has the major advantage of producing gaseous deoxidation products and not NMIs, intense stirring with its various advantages, and allows for time management in the logistics of ladle flow, therefore on the quality of temperature control of liquid steel - including reheating by aluminum and oxygen injections (RH-OB, CAS-OB), cf. Figure 2.

Continuous casting (CC) was also at the time overwhelmingly taking over the solidification function in the steel shop [19], because it increased metal yield, cut cost and make it possible to improve steel quality at the same time. CC imposed a new sophistication on the control of steel temperature in the ladle, i.e. on superheat in the tundish and this was made easier to manage by dedicating a specific area of the steel shop to secondary or ladle metallurgy (S/LM). Additions for deoxidation and alloying were carried out there, and several other functions were added, a mixing function (by gas stirring or purging or by electromagnetic stirring), and, à la carte, vacuum degasing and heating, with an electric arc or, less frequently, plasma torches, induction heating or aluminum oxidation in the melt. The outcome of this evolution was that secondary metallurgy became a permanent feature of the steel shop; it often included vacuum and preheating devices in steel shops both for long and flat carbon steels. Stainless steelshops had their own specialized reactors, usually VOD or AOD, to cater to the special needs of chromium metallurgy.

S/LM became a marvelous tool to manage steel cleanliness: addition under controlled conditions became possible, but also careful slag-metal stirring, slag reduction, temperature trimming, inclusion coalescence, elimination by flotation and entrapment in the slag and composition control, vacuum degasing and sometimes carbon deoxidation, etc. The functions available for engineering steels thus became available to all steel producers and a subset of them were used for all grades of steel: the distinction between commodity and specialty steels thus became blurred.

One important feature of S/LM and CC is that the metallurgical functions are spread out in space along the equipment line, deployed as along a time scale, and therefore they can become standardized, sometimes 


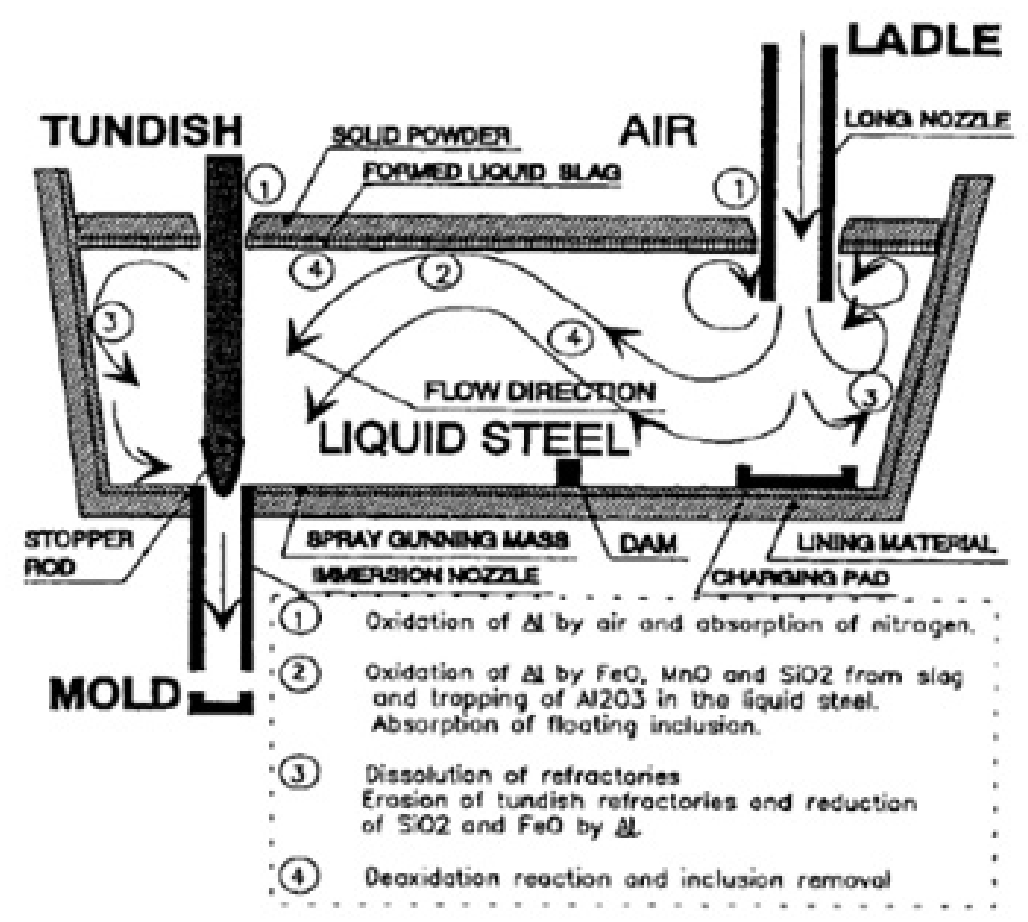

Fig. 3. Schematics of phenomena taking place in the continuous casting tundish in connection with steel cleanliness.

automated and better controlled. On the other hand, sources of contamination have multiplied but can also be better controlled: ladle to tundish (ladle nozzle, sliding gate, ladle stream gas protection), tundish (powder, weirs, dams and baffles, bubbling elements, etc.), tundish to mold (nozzle, sliding gate or stopper rod, submerged nozzle and gas bubbling, etc.), mold (mold powder, mold level control, submerged nozzle geometry, etc.), CC itself (straight, curved mold, straight mold and curved, electromagnetic stirring, electromagnetic brake, transversally-shaped molds of thin slab casters, etc.), all have become part of the process chain and turn into true metallurgical reactors. The expression "tundish metallurgy" has become common lore (for example cf. Fig. 3).

The continuous caster, especially its mold, also act as a metallurgical reactor where the fate of NMI continues to be decided (cf. Fig. 4) [20,21].

Much of research and development work focuses on the various devices that can be imagined to mitigate NMIs.

Note that completely new issues in terms of cleanliness were raised by the introduction of continuous casting: after searching for the martingale to cast rimming steels on CCs for many years with limited success, steelmakers understood the advantages of aluminum grain-controlled steels, which triggered the overwhelming move to aluminum deoxidation, away from rimming steel or semi-killed grades.

However, alumina was collected by nozzles. This reduced the number of heats during sequence casting ${ }^{13}$ and resulted in catastrophic events, when the inclusion plug got accidentally discharged and trapped in the bloom or the slab. This issue was particularly acute in the case of thin slab casting (TSC).

A technique to prevent clogging was reinvented, consisting in changing the nature of inclusions by a treatment in the ladle, with calcium as the inclusion modifier: simply put, calcium aluminates, with a composition close to the eutectic in the $\mathrm{Al}_{2} \mathrm{O}_{3}-\mathrm{CaO}$ phase diagram, are liquid at the temperature of operation and thus will not deposit in the nozzle (cf. Fig. 5). This technology has been used systematically in the case of TSC,

\footnotetext{
133 ppm of oxygen contamination generate $1 \mathrm{~kg}$ of inclusions in a $100 \mathrm{t}$ heat.
} 

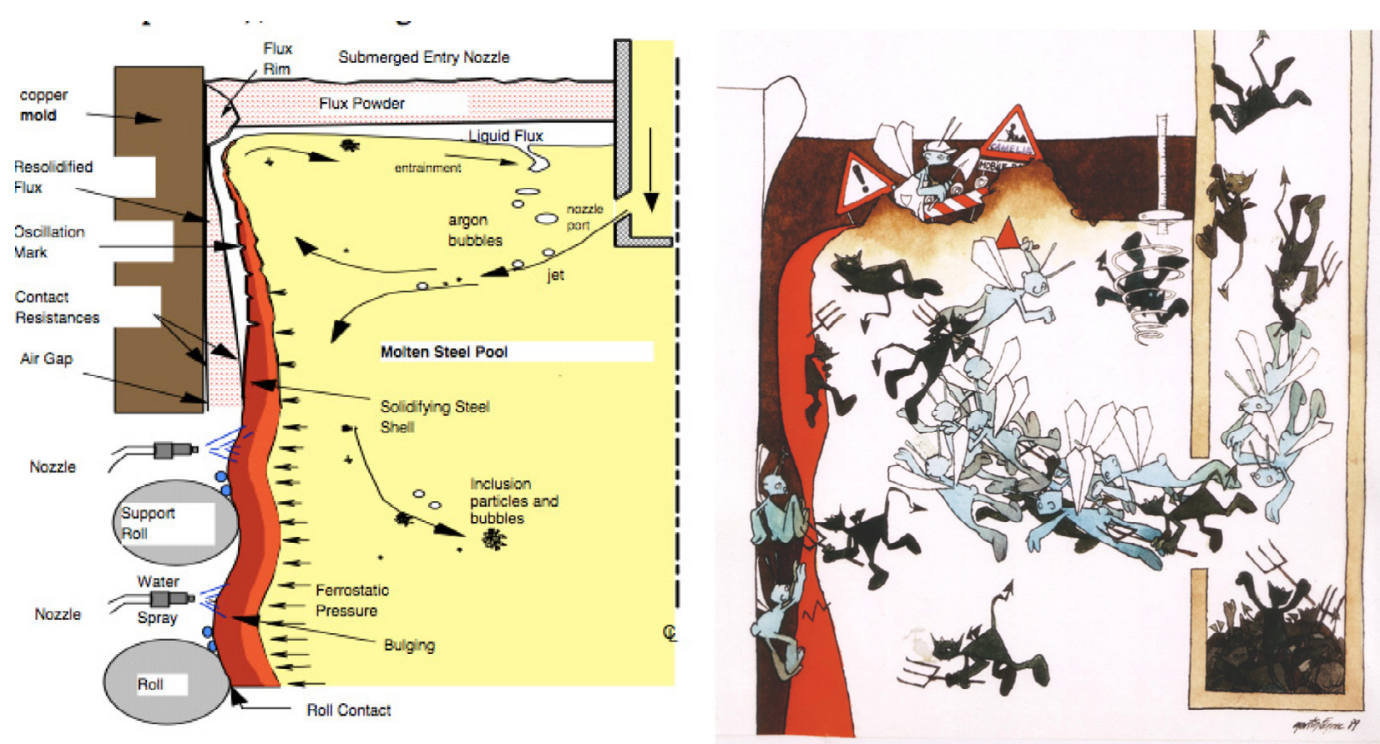

Fig. 4. Schematics of phenomena taking place in the continuous casting mold in connection with steel cleanliness ${ }^{14}$.

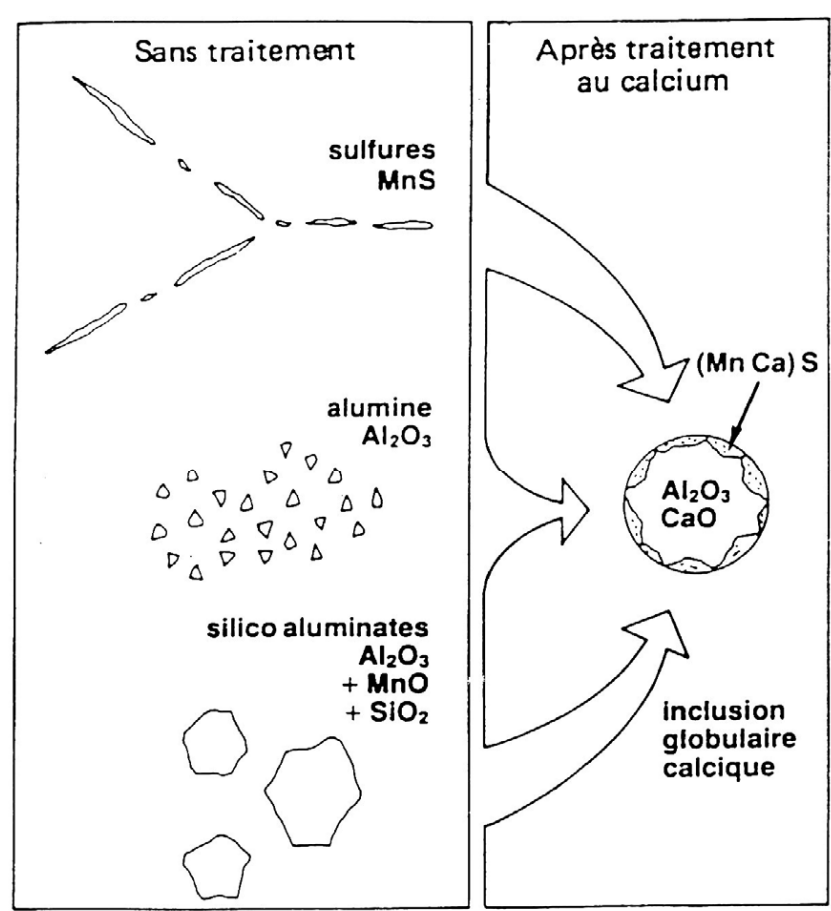

Fig. 5. Modification of the nature and morphology of inclusions by calcium treatment (sans traitement: no treatment, après traitement au calcium: with Ca treatment); sulfures: sulfides; alumine: alumina; inclusion globulaire calcique: globular calcium inclusion).

while other solutions were preferred in the case of slab casting, based on argon injection in the submerged nozzle and on curved casters with a vertical mold.

While CC and S/LM were becoming mainstream process technology, the production of high-end engineering steels continued to explore more advanced cleanliness and developed original production routes based on remelting, especially under vacuum (VAR) [22]. For slightly less demanding applications (bearing steels for races, tire cord, piano wires), vertical continuous casting of large sections was developed and a few examples of such casters exist across the world for these niches.

For making seamless tubes, a special process was developed in which round billets were cast and the mold and billet rotated so that the meniscus developed as a vortex and NMIs accumulated at its center, thus ensuring that the outer skin was clean of them. This Centrifugal Continuous Casting (CCC) technology developed by Vallourec has now mostly been replaced by standard $\mathrm{CC}^{15}$.

14 The cartoon from the right-hand side of the picture is part of a series developed by Ecole des Beaux Arts of Metz in the 1980s to illustrate continuous casting technology for didactic purposes. The blue "angels" are working in favor of the quality of the slab, while the black "devils" try to destroy it.

15 Developed in the 1960s, this technology aimed at a particular niche by solving a specific 


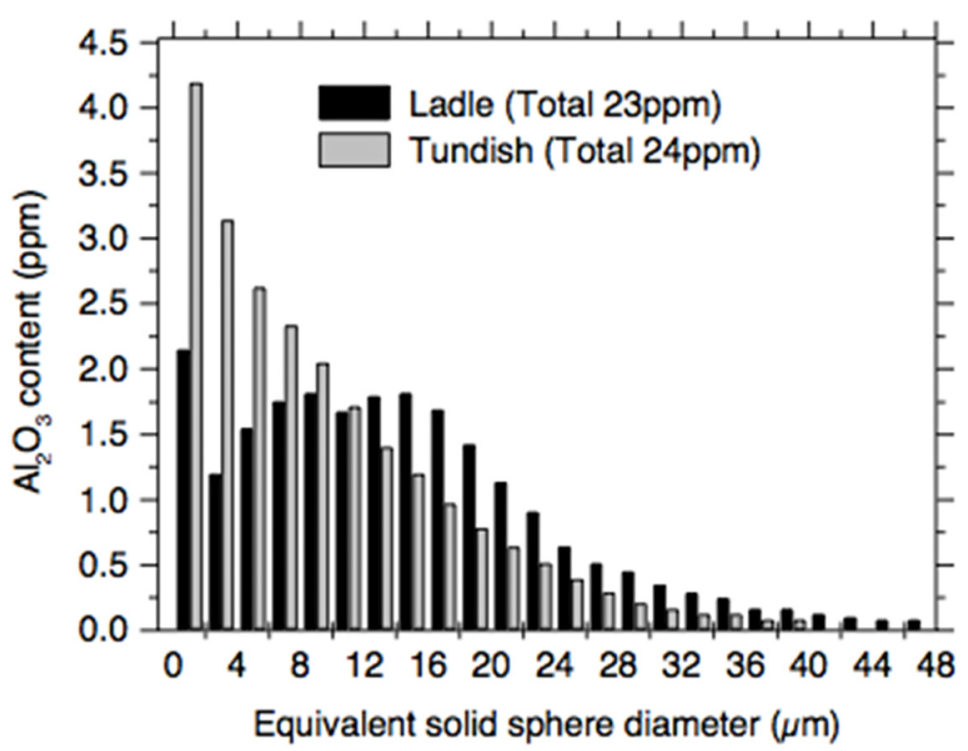

Fig. 6. Alumina inclusion size distribution in the ladle and the tundish [26].

\subsection{Cleanliness estimation and measurement}

The ideal estimation of cleanliness would describe each NMI in an exhaustive way, thus by its composition, size, shape and location at the scale of the total system (e.g. the steel ladle or the cast heat). This is impossible to accomplish - although X-ray tomography (CT, Computerized Tomography), making use of a synchrotron source, is progressing rapidly $[23,24]$ - except if some specific defect is targeted and controlled in an exhaustive way: e.g. cold rolled coated sheets checked for surface defects by operators or automatic devices, bars or plates controlled by ultrasonic or eddy-current devices ${ }^{16}$, etc.

Therefore, statistical estimates have to be used.

issue in an original way. Steels were siliconkilled and liquid steel was injected in the mold tangentially by a special refractory device and with an open stream. Since then, the idea of a standard, "one size fits all" CC technology was adopted. Technology variants got relegated to footnotes and historical papers, except for Thin Slab Casting, the last major breakthrough innovation related to $C C$.

16 These methods are used to monitor all kinds of defects and are not focused directly on inclusions, which in some cases may be below their threshold of sensitivity.
"One kilogram of typical LCAK steel contains $10^{7}-10^{9}$ inclusions [3], including only four hundred $80 \mu \mathrm{m}-130 \mu \mathrm{m}$ inclusions, ten 130-200 $\mu \mathrm{m}$ inclusions and less than one 200-270 $\mu \mathrm{m}$ sized inclusions" according to a classical paper by Kiessling published in 1980 [25].

Cleanliness can be estimated at various times in the steel production process chain or on the solid product, cf. Figure 6 . The former estimates are made in order to monitor steelmaking, casting or rolling practices and subsequently to rate the quality of a particular heat and thus to accept or to reject it (quality management), or to modify the practice and improve it in a process of quality improvement, including research analyses and introduction of new technologies.

To monitor the cleanliness of steel across the process route or to compare historical evolutions, total oxygen $\mathrm{O}_{t}$ still gives useful global estimates of trends. A simple derivation of the connection between $\mathrm{O}_{\mathrm{t}}$ and inclusion size distribution is shown in Figure 7.

Estimating inclusion size distribution, especially when the larger sizes are the real concern, is more complex and always ends up in a compromise. To obtain statistically significant information, two directions have been explored: either observation of large surfaces or volumes (e.g. automatic image analysis, sometimes on samples produced 


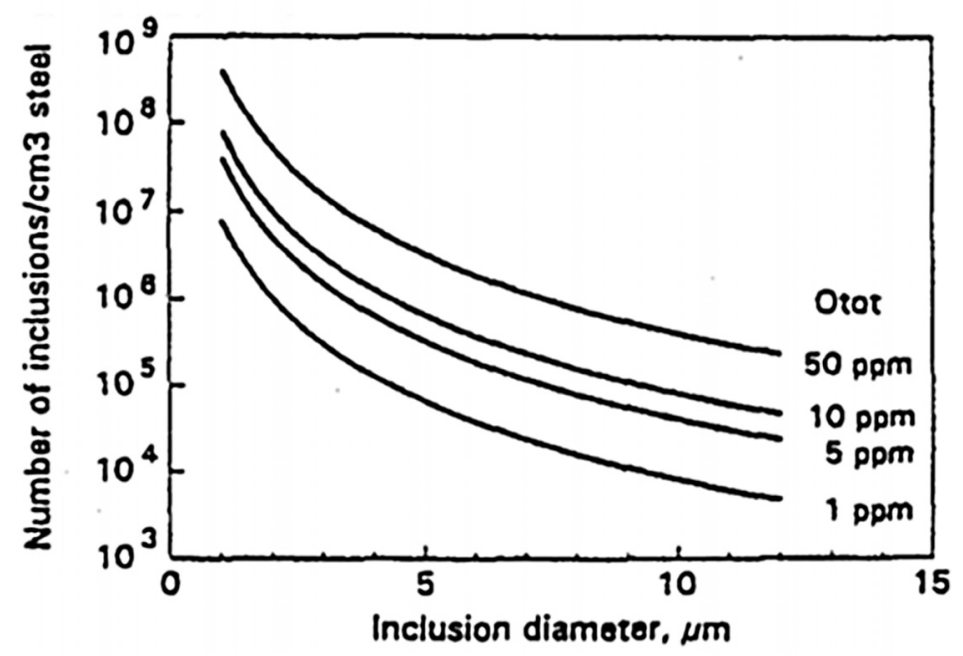

Fig. 7. Number of inclusions in $1 \mathrm{~cm}^{3}$ as a function of $\mathrm{O}_{\mathrm{t}}$ and inclusion size.

automatically) or some kind of three dimensional monitoring (e.g. electrolytic dissolution of a sample and granulometric analysis of the resulting sludge (slime method), MIDAS method (forging of a tundish sample in order to weld porosities and to elongate inclusions, then US testing of the deformed sample), LIBS analysis of liquid steel samples (e.g. LUS lollipop)), etc. Steelmaking is still looking for the Grail in this area, although existing methods already provide much useful information.

One trick to guess at the dimension and number of large-size inclusions that cannot be observed - except by chance - is to execute a statistical sleigh of hand, whereby the distribution of inclusions, measured at small or intermediate dimensions, is extrapolated to the larger sizes (Statistics of extreme values (SEV) method) $[27,28]$. Practically, there are several inclusion populations in solid steel, due for example to deoxidation, reoxidation, various other contamination mechanisms and process mishaps, and therefore the case for all of them to align along a single distribution curve is fairly weak! The extreme values estimated in this manner are fuzzy at best!

Note that there are biases when sampling liquid steel to obtain cleanliness information, as the sampling operation, unless carried out under special conditions with argon injection for example, can lead to an oxygen pick up of as much as 35 ppm; moreover, in- clusions float up in the sample, like in any liquid metal vessel, etc.

Finally, there are many transient phenomena (first heat in a sequence, end of ladle, change of ladle, change of ladle tube, speed changes on the continuous caster, change of submerged nozzle in the caster mold, change of tundish, etc.), which cause time variations during a casting sequence and may lead to the deterioration of cleanliness, which is best handled by downgrading part of the production.

\subsection{Cleanliness, steel properties during processing and in use, steel quality}

The limiting case of rouverain iron, which breaks up under the blacksmith's hammer makes the point that foreign phases in steel can affect steel processing - if they are present in large quantities and large enough sizes - and also steel properties, either their bulk level or their spread.

This is the basic reason, of course, why so much interest has been devoted to NMIs and to cleanliness.

NMIs carried over into the CC mold can cause various kinds of defects during continuous casting, including breakouts or major surface defects.

Many NMIs are trapped in the metal at solidification. Then another of their properties becomes paramount, their plasticity 


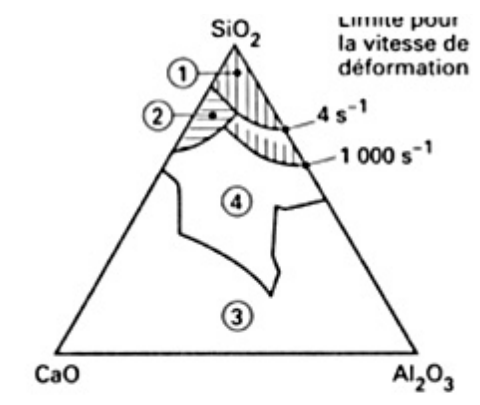

- A hard inclusion under rolling conditions

- idem

(1)
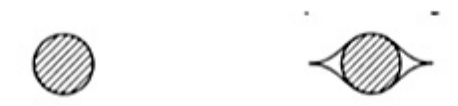

idem

(2)
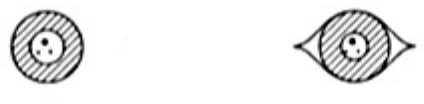

- A hard crystalline inclusion broken during rolling

- A hard inclusion cluster strung out during rolling

- An inclusion composed of hard crystals dispersed in a soft matrix

- A soft inclusion under rolling conditions
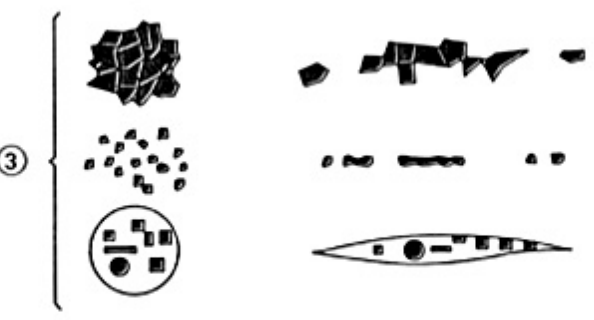

(4)

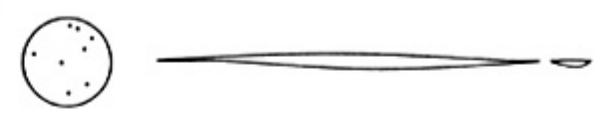

Fig. 8. Fate of non-metallic inclusions depending on their plasticity during hot deformation [29].

compared to that of the metal matrix: indeed, NMIs will deform during hot forming, either congruently or differently - to the point of breaking up -, align with the deformation and create "weaknesses", like separations and internal cracks (e.g. lamellar tearing) or traps for hydrogen, plus an anisotropy between longitudinal and transverse directions (cf. Fig. 8). Inclusions can also emerge at the surface and create superficial defects, which can be unaesthetic or initiate cracks or corrosion. In tough, high strength steels, some inclusions can behave as internal cracks, even if there is continuity with the matrix, and thus influence fatigue properties in a detrimental way, in effect significantly decreasing the fatigue limit of steel [30].

This has also been a rich domain for R\&D.

All of these phenomena are mainly related to the larger inclusions, but the general level of cleanliness remains a factor, in as far as large inclusions are less frequent in clean steels. This is the reason why the very highend applications resort to remelting under vacuum, after a step of very clean production of the remelting electrode.

The complexity of the phenomena that control cleanliness, their transient nature, the occurrence of operating mishaps or accidents, as well as the imperfection of the methods available to monitor cleanliness in a satisfactory quantitative way, make it such that high-level performance requires continuous tension and that crisis of defects cannot be avoided, the cause of which is always long and painful to identify and to correct.

The connection with steel properties, during processing and in use, is also complex and not fully understood in the real time monitoring of steel production and of steel quality. Steel producers have been developing methods to improve performance in this domain, like the Global Product Quality System (GPQS) of ArcelorMittal [31], which monitors carbon steel coil quality - in a general way and without a particular focus on cleanliness; moreover, the technologies are not widely reported in the literature as they are in part proprietary. 
The steel sector is quite different from manufacturing sectors, which deal with simpler physics and thus with more reproducible phenomena. Steel indeed has not reached the same level of reliability and predictability and it may never do so. This is due to the complexity of steel processes that extend from physical chemistry to technology in connection with the very high production volumes involved.

Some level of complexity should probably be accepted as a limit to some overrational practices and considered as a strength rather than a problem! A steel mill is not a car manufacturing plant and therefore it will probably never be run as one! This is an important caveat to keep in mind, when narratives like integrated intelligent manufacturing (IIM) [32] and Industry 2.0 are marketed across the media.

\subsection{Provisory conclusions}

A first conclusion is that the cleanliness of steel is a story that has been told since the 1980s and 1990s. Thus research in the field does not necessarily connect with innovation any more, at least radical innovation. This is due to the fact that the innovation drivers in the steel sector have matured and saturated 20 or 30 years ago (mass production, quality management, cost control and product engineering) [33]. This is unlikely to change until a new driver takes over, which, most likely, will be related to sustainability and to environmental issues.

This connects wit the next section of this paper.

Research has not stopped, however, even if it has slowed down significantly. It is now directed at maintaining the state of the art of process technologies, in terms of modeling, instrumentation and control and of adapting technologies which have become standard and have proven their robustness to new product challenges and generally new contexts and maybe eventually new innovation drivers.

On the other hand, emerging economies have adopted steelmaking technologies as they were, marketed by sophisticated and powerful engineering companies, and are demonstrating an acute ability to push them quickly to their limits and beyond.

Large global companies use their research teams not to innovate in the process sector any longer, but to make sure that the practices of their best mills, usually located in Europe, are transferred seamlessly to their mills in the rest of the world. As a matter of fact, the large European companies are almost invisible in the present Clean Steel conference!

\section{Clean steelmaking}

The very basic reason why clean steels can no longer be considered as a self-centered issue looking at steels from the inside, is that making steel is about sorting out nonferrous elements and discarding them, when they work against the purity of the metal: the main, profit-making product on one side and by-products or waste on the other side. This then leads to two questions:

- how are these discarded substances handled, in term of environmental issues and of sustainability? Is a clean, sustainable steelmaking meant in a holistic sense possible?

- Is not there a different way to approach things, using raw material without transforming them as much as is done in today's technological paradigm? Like, $m u-$ tatis mutandis bio-based materials (wood, natural textiles) do?

Note that the approach used to make steel today is quite general in designing and making any material, including more emphatically the new ones: select the best possible set of elements from which to make a material in order to fulfill the targeted property at the highest level possible and then deal with sustainability issues as a corrective measure, some would say as an afterthought.

Much of the present problems related to the scarcity and geopolitical status of raw materials are due to this attitude of product and material designers, which aim at the highest level of performance without much regard to resource efficiency and thus to eco-design. 


\subsection{Raw material utilization and the circular economy}

Raw materials for steel production - iron ore and coal mostly - are neither rare nor scarce, except for a very few alloying and reactant elements, for the fundamental reason that iron is the most abundant element in the Earth and a fairly common one as well in the Earth crust [1]. This does not mean, however, that they will be used indiscriminately in the future, because steel is presently already recycled to a high level ( $83 \%$ and 36 years of average life) [34] and, when peak steel production is reached, probably towards the end of this century, a full circular economy will take over, except, possibly at the margin for a small number of niche applications.

When steel is recycled, the alloying elements and ternary phases that it contains are recycled as well: while some will be oxidized out of the steel at steelmaking and incorporated into EAF slag (silicon, half of the manganese, part of the chromium, most of sulfur and phosphorous, molybdenum, rare earths, aluminum and other deoxidizing agents, all of the ternary phases), or vaporized (zinc from coatings, some sulfur emitted as COS), others will be diluted into the steel matrix and thus either dissipated (tin) or co-recycled (part of the manganese, most of the chromium, nickel). Only the non-recycled steel will be dissipated or absorbed in the "urban or anthropological mines" (ships sunk at sea, legally or illegally landfilled material, hidden scrap piles, deep foundations of buildings, etc.).

A quantitative and exhaustive mass balance of all items involved in the steel value chain is not readily available, although the main orders of magnitude are not in doubt.

The iron ore used today has skimmed the best deposits of high-grade ore that can be shipped directly to the steel industry, either as natural ore or after beneficiation. Even with such a favorable scheme, the mining industry discards between half and two thirds of the material removed from the mine $^{17}$, usually as tailings, in addition to the overburden of rocks inside which the ironrich deposit is geologically enclosed. Tail-

\footnotetext{
17 Except for exceptional mines like LKAB's in Kiruna, where virtually pure magnetite is mined.
}

ings constitute a slurry, which is difficult to dry and therefore is stored in natural valleys, behind dams. The tailings also concentrate heavy metals in the slime and in discharged water, which has to be treated accordingly. Tailings and the conditions under which they are stored constitute one of the major environmental burdens carried by the steel value chain. The issue will disappear, when the recycling economy fully takes over towards the end of the century. An opportunity to use some of these tailings would be to use them as raw materials for the ULCOWIN process, which needs lowgranulometry ores dispersed in an aqueous solution (see further in the text).

In the future and during the 80 years or so when ore will continue to be used in high volumes, less pure ores will be called upon and therefore the energy needs for steel production will increase, while its purity will decrease [35]. The same will eventually be true for the secondary raw material route (scrap), which will become enriched in nonferrous elements ${ }^{18}$.

\subsection{Energy needs and energy transition}

The steel industry because of its nature (reduction of an iron oxide by carbon, which involves breaking a strong $\mathrm{Fe}-\mathrm{O}$ bond) and of its size (1.6 billion tons in 2014) is known as an energy-intensive industry, along with other material producing sectors and with chemistry. This is often taken as a value judgment, even though it is only a scientific fact that should be judged in a cost-benefit analysis of the proper ambition: "no pain, no gain!" as Benjamin Franklin put it, or, in physics language, there is no work without exergy.

Steel is not particularly energy-intensive as compared to other materials [36]: indeed materials are in essence all energy intensive, which is the price to pay for the functions

\footnotetext{
18 This is not a problem today, because the elements that are not recycled are diluted by the input of purer primary raw materials. Technology is available for recycling some of these elements, but it is mostly not used today, for lack of economic and ecological incentives.
} 
they provide to society. Moreover, the energy involved is mainly exergy, not simply heat dissipated as is the case for combustion processes.

In a practical way, the steel sector has achieved a high level of energy efficiency pulled by the driver of cost cutting ${ }^{19}$ and therefore the leeway left open for improving it further is small, of the order of 10 to 15\% [37]. Higher levels could be achieved if radical changes in the steel production processes were introduced (thus reaching 15 to $25 \%$ of energy efficiency increase) [38]. However the business model for introducing these changes is still elusive, which means that the cost of introducing more energy savings is far higher than the value of the energy saved.

The energy transition, which is taking place now and especially in Europe with different flavors in each country, is also a challenge for the steel sector. Steel has been organized around the use of the cheapest energy sources and therefore renewables can only be introduced through the electric grid, hic et nunc.

However, the ULCOWIN process, proposed as part of ULCOS' solutions, can play an important role in a grid fed by a large proportion of renewables: indeed, large steel mills based on electrolysis could contribute significantly to the grid management in the face of the intermittency of green electricity, by introducing a strong and significant option for demand-side load management [39]. This is a long shot, but the energy transition is also a long-term endeavor!

More options to integrate renewables in the steel sector will probably emerge in the future.

\subsection{GHG emissions of steel production and transition to a low carbon economy}

Regarding GHG emissions, the ambition of the UNFCC is to cut emissions by $80 \%$ by 2050 in order to avoid a surface temperature increase of more than $2 \mathrm{C}$. This cannot be achieved in the Steel sector by implementing energy efficiency solutions, which

19 Energy costs account for roughly 20\% of operating costs in an integrated steel mill. fall short of the target by a factor 6 ! New breakthrough processes are needed and a path for achieving this has been outlined in the ULCOS programs [40], proposing a series of "ULCOS solutions", based either on smelting reduction and CCS, in a modified blast furnace or a liquid metal smelting vessel (ULCOS BF and HIsarna), or a streamlined direct reduction furnace implementing CCS as well (ULCORED) or two electrolysis options, based on the use of carbon-lean electricity (ULCOWIN \& ULCOLYSIS). These solutions have matured to different levels of TRL, the most advanced one, ULCOS-BF has been engaged to level 7 . These are long-term endeavors, maybe still 10 years or more in the future, requiring very large R\&D budgets, especially when demonstrators are to be built.

Engaging in these major changes for making steel with greatly reduced $\mathrm{CO}_{2}$ emissions is similar to engaging in the energy transition. The change will only happen when R\&D is finished and confirmed at TRL 9 and when a "business model" is developed in connection with the world governance of climate change policies - as any climaterelated transformation is today still an externality in the market economy. Moreover, a world level playing field to avoid carbon leakage will also be necessary and COP21 might bring the necessary framework for achieving this. There will be a progressivity of introduction of the new technologies, if and when these conditions are met, but its kinetics will not run in parallel with the evolution announced by the Commission in July $2015^{20}[41,42]$.

Beyond the discussions around free allowances to avoid carbon leakage and the continuous bickering regarding how to adjust these, a radical solution would consist in moving the steel sector out of the ETS

\footnotetext{
$202.2 \%$ linear reduction factor of the annual emission cap, compared to currently $1.74 \%$ (20132020). $1 \%$ annual reduction of benchmark values, i.e. at least $15 \%$ below the current level of most efficient installations. However, free allocations based on carbon leakage assessment are maintained under certain conditions and new schemes for funding the development of breakthrough technologies are proposed (NER 400, plus an innovation fund for demonstration of breakthrough technologies).
} 


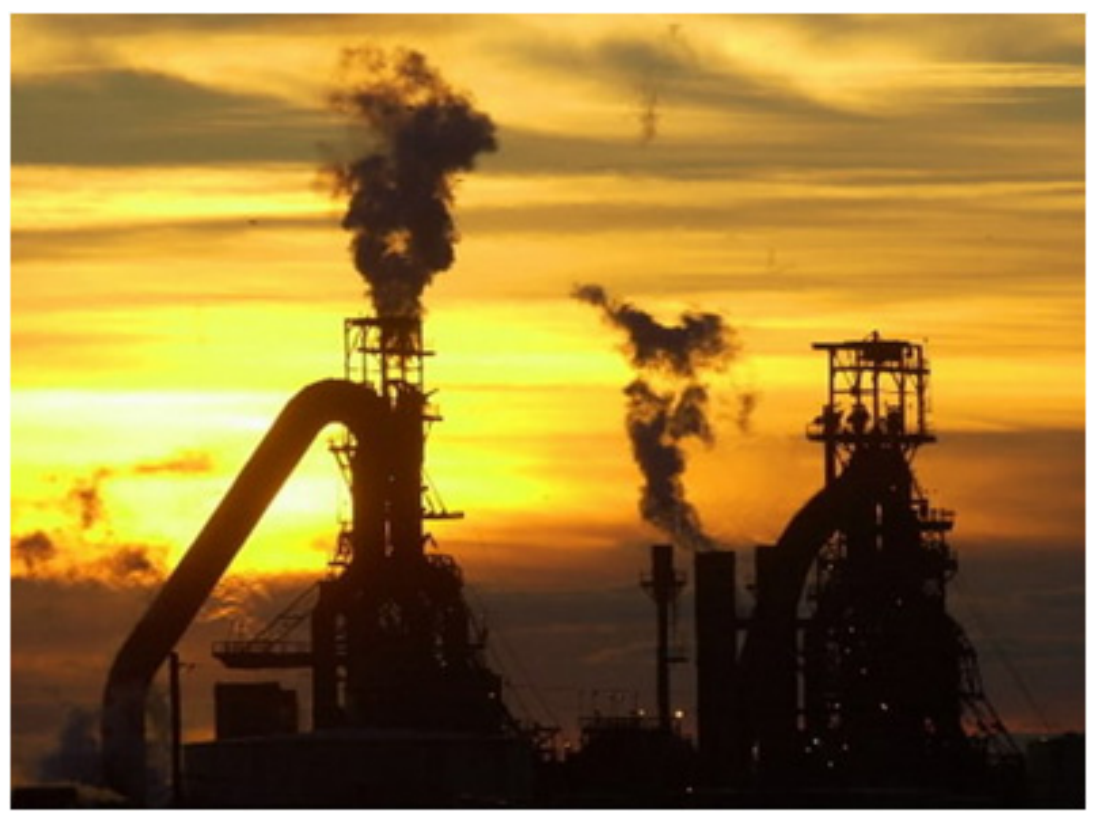

Fig. 9. Air pollution is not easy to photograph coming out of a smokestcak and, therefore, the media tend to show plumes of steam, which have absolutely no environmental impact.

until breakthrough solutions are available, while putting in place mechanisms to ensure that these technologies will actually be developed [43].

One should also acknowledge that the steel sector, worldwide, is seriously and unambiguously involved in the circular economy, with world-record recycling rates achieved on a regular basis, and therefore that the long-term future of the blast furnace route is already compromised and will dwindle to a niche production, eventually. The point then is to decide whether transforming the sector for the coming 50 years or so is worth it, in terms of cost of investment, in particular, in light of the $\mathrm{CO}_{2}$ emissions that would be avoided.

\subsection{Air emissions}

Air pollution has been traditionally associated with steel mills, long after most problems had found solutions (Fig. 9).

Some of the elements separated from iron leave the ironmaking or the steelmaking reactors as dust or volatiles.

Dust, otherwise known as particulate matter (PM), originates from ore piles, sinter plants (the most profligate emitters), coke ovens, blast furnaces, steel shops, roughly 10 to $20 \mathrm{~kg}$ per major reactor; more dust comes from downstream, at every smokestack, but less in volume. Most of the dust is collected and either recycled (in the integrated mill at the sinter plant, or externally for example in a Waelz kiln to recover zinc from EAF dust) or marginally landfilled. Air pollution issues related to dust were handled in the second half of the 20th century, especially since many steel mills were quickly enclosed in cities subject to urbanization growth.

Volatiles emissions are related to heavy metals (cadmium, mercury, nickel, copper, zinc, lead, etc.), inorganic compounds $\left(\mathrm{H}_{2} \mathrm{~S}\right.$, $\left.\mathrm{CO}, \mathrm{SO}_{x}, \mathrm{NO}_{x}, \mathrm{O}_{3}\right)$ and organic compounds (PAHs, dioxins and furans, VOCs, POCs, etc.).

Air pollution has been brought under control at the best-run steel mills of the world, following very active research and abatement technology development. Moreover, lists of technologies to guarantee conformity to present standards have been compiled, for example by the European Commission [44].

Besides these "elite" mills, however, there are still air pollution issues in parts of the world [45]. Moreover, the standards are very likely to be raised to much tougher 
limits by the middle of the century [46], due to increased urbanization, to the fact that locating production plants away from cities will no longer be an option and to several air pollution issues stepping up from local to global scale (cf. Fig. 10).

The discussion should now address emissions to water and emissions to soil, but it will be kept very short. These issues have also been scrutinized at the end of the 20th century, regulated and carefully monitored, for example in Europe, so that problems have dwindled. Some European steel producers like to state that the water they discharge is cleaner than the water they take in and, anyway, recycling water internally in the steel mill has become the norm [47] and, in the EU, the specific consumption of water of the steel industry is negligible compared to some other parts of the world.

Soil pollution is mostly a legacy of the past, an archeological signature of steel mills long shut down. As a matter of fact, soil and water table pollution went hand in hand at that time, but this has been long past.

\subsection{Biodiversity and more holistic issues}

Biodiversity is a global threat to the ecosphere and trends seem to announce the 6th largest biodiversity extinction in the history of the planet [48]. The United Nations have pointed this danger out as early as the Earth Summit in Rio, in 1988, when the Convention on Biodiversity was launched [49] at exactly the same time as the UNFCC. A sharp reduction in biodiversity endangers the ecosystem of the planet as a whole, or at the very least, announces major evolutionary changes, at a scale that was never observed in human history.

Steel, as an economic sector or a material, cannot be considered as causally connected to or partly responsible for this biodiversity or its loss - except at the local scale of steel mills and mines, where regulations and legislation has provided a framework that steel and mining companies follow. However, globally, the industry itself is threatened as an element of society and, furthermore, it holds part of the solutions to alleviate the risk. The loss in biodiversity being related to climate change and to the increase in the urban footprint, industry can act globally by reducing its GHG emissions and by abating the impact of cities, for example in providing biodiversity or ecological corridors, a new kind of large scale infrastructures, which will need a strong material backbone based in part on steel. This is another example of the slogan "steel is part of the solution", which should probably read as a scientifically optimistic statement regarding how the present technological episteme is flexible and plastic enough to address radically new challenges and new problems.

\subsection{Societal challenges and steel anthropospheric services}

Materials and steel are deeply woven into the present technological episteme and have been playing such a role across many more past ones. Materials have been used to create barriers between the ecosphere and the anthroposphere, because, from a physical standpoint, they can sustain large gradients of temperature, stresses or chemical potential. Inside the anthroposphere, they separate the space where people live and work from the reactors of the technosphere, where conditions are decided by engineers and not friendly to life, like a blast furnace, a distillation tower or a nuclear reactor [50]. The energy system, from energy harvesting, electricity generation to energy distribution through power or pipe lines, relies heavily on steel, which constitutes its backbone and its structure, inside which more specialized functional materials like copper, silicon, or fiber-reinforced composites assume specific missions [51].

Steel producers sell steel to make power plants or power poles but not to assume the function of holding and tying the energy system together. This constitutes a service that is mostly taken for granted and thus not monetized. The concept is similar to the ecosystem services that biodiversity delivers to the biosphere and the anthroposphere. We have called them anthropospheric services (AS). It would probably be possible to estimate their monetary value, following the methodology followed for climate change or BES [52,53], but the work remains to be done. 


\begin{tabular}{ccccccc}
\hline Substances & 2000 & 2010 & 2020 & 2030 & 2040 & 2050 \\
\hline $\mathrm{GHG}$ & $0 \%$ & $10 \%$ & $20 \%$ & $30 \%$ & $40 \%$ & $50 \%$ \\
$\mathrm{VOC}$ & $0 \%$ & $24 \%$ & $49 \%$ & $60 \%$ & $70 \%$ & $81 \%$ \\
$\mathrm{SO}_{x}$ & $0 \%$ & $20 \%$ & $75 \%$ & $77 \%$ & $80 \%$ & $82 \%$ \\
$\mathrm{NH}_{3}$ & $0 \%$ & $0 \%$ & $27 \%$ & $44 \%$ & $62 \%$ & $79 \%$ \\
$\mathrm{PM}$ & $0 \%$ & $0 \%$ & $50 \%$ & $50 \%$ & $50 \%$ & $50 \%$ \\
$\mathrm{NO}_{x}$ & $0 \%$ & $26 \%$ & $53 \%$ & $64 \%$ & $74 \%$ & $85 \%$ \\
Others & $0 \%$ & $10 \%$ & $20 \%$ & $30 \%$ & $40 \%$ & $50 \%$ \\
\hline
\end{tabular}

Fig. 10. Evolution of emission targets for various indicators and output streams as projected from 2010 to 2050.

Contrary to the issues discussed in the previous sub-sections and related to the negative effects of industrial activities on the ecosphere or the anthroposphere, AS are a positive contribution of steel to society and to the resolution of the societal challenges which the European Commission stresses, for example, in its Europe 2020 agenda [54]. This approach does not fully cover the scope of the assets that steel, materials or industry in general provide. For example, industry is widely expected to provide jobs and thus to contribute to monetary flow and to economic growth, but also to participate in the creation of well-being, as steel, like many commodities in the economy, has been directly connected to GDP per capita [4]. All these issues cover what we have called the social value of steel.

The liabilities of industry have been covered more extensively in publications, approaches (LCA) and narratives than its assets: this remark was indeed one of the starting points of the SOVAMAT initiative [55] and of the series of Society and Materials seminars (SAM) [56].

\subsection{Provisory conclusions}

The section on clean steelmaking has been presented in a classical way, thus starting from environmental issues, enlarging the viewpoint to sustainability and then to the social value of steel, a common attempt at reaching some level of holism.

The approach differs from that of the first section, because the figures involved are completely different in nature: larger (up to one order of magnitude higher than iron's and not ppm), less precise or well known (the amount of published work is much less abundant), less specific (there are elite mills and others).

Moreover, the discussion on clean steelmaking describes the interaction of the steel value chain with the ecosphere (harvesting of natural resources, role of secondary raw materials, creation of ancillary material flows [waste, co-products, by-products, residues], emissions to air, water and soil, sometimes pollution, contribution to anthropogenic emissions of greenhouse gases, interaction with biodiversity and BES) or with the anthroposphere (emissions becoming pollution, work health and safety issues, public health issues, positive value of steel, anthropogenic services rendered by steel to society, etc.). These descriptions are less finely analyzed and quantified than the first part on steel cleanliness and they tell stories, narratives, rather than state scientific facts [57]. The objective is conformity with an ideal which would preserve the environment, save it for future generations: this has been turned into targets and standards by hoards of legislation at country and supraregional levels, like the EU: in Western-style countries, where this approach has been strong, one can consider that the contract has been met, until more issues are raised and the severity of regulations increases accordingly in the future.

However, this is the other face of the coin, if one ambitions to speak about clean steels in a holistic way. Indeed, steel is a major material produced by industry to provide society with anthropospheric services. To do so, the present technological episteme provides solutions to collect the element iron from primary or secondary resources and in doing this, mines much larger resources, which are then sorted out and transformed 
into primary (iron and steel) and secondaryancillary (waste, emissions) flows. The secondary flows are different from natural resources, which were in equilibrium with the environment, being displaced spatially and more concentrated, sometimes to the point that they need to be treated to cope with a new toxicity to the ecosphere or to the anthroposphere. Thus, clean in the sense of steel production does not mean purity but rather returning the secondary flows to their initial complexity and state of mixing, diluting them to regain their primal natural essence (purity?) ${ }^{21}$, therefore quite the contrary to what was targeted in clean steels.

As was pointed out in several subsections, some of the underlying issues are still open and will require much more work, including research and development in the future. This is the case of low-carbon steel production, which needs to demonstrate promising technologies like ULCOS solutions at a larger scale, but also of biodiversity issues, where more thought is needed to identify how the steel sector can contribute to solving this huge societal challenge. Moreover, as emissions targets will become more severe in the future, more technology will have to be invented and deployed.

Last, there is a vacuum in methodologies to deal with these matters. One can consider that LCA and MFA are a first step in the proper direction, but the former focuses on the value-chain of a specific consumer (sub-)items, while the latter focuses on monitoring the flow of specific substances or elements in the economy, mainly as a function of time. What is still missing is a mass flow description of the shower of primary and secondary materials/residues generated by a value chain (like steel's) and of their fate, thus the grafting of an MFA approach on an LCA framework.

There is thus much more work left to do in the area of clean steelmaking than in that of clean steels.

\footnotetext{
21 Diluting has been considered as a "no-no" in ecological thinking, because it did not deal with issues close enough to their causes. The idea put forward here is of a different nature as it talks in favor of dilution as a restoration of natural equilibriums.
}

\section{Conclusions}

The concept of cleanliness in connection with steel has been discussed extensively in this paper, in line with the objectives of the long series of Clean Steels conferences.

On the one hand, steel cleanliness is a concept which has been worked out extensively and probably exhaustively on the basis of the needs of the present technological episteme. The construction of the concept of cleanliness has been contemporary and parallel to the construction of the concept of the modern steel shop, with its systematic use of ladle-secondary metallurgy and of continuous casting.

Clean steels aim at minimizing the amount of ternary non-metallic phases that precipitate by physical-chemical equilibriums, when liquid metal cools down and solidifies and those that originate from contamination by atmospheric oxygen, slag, powders and refractories. Thus cleanliness goes along with purity and part of the problem is solved prior to the final trimming of steels in the ladle, by cutting sulfur and phosphorous levels on hot metal or during conversion and by the generalization of deoxidation by wire injection rather than ladle additions - thus renouncing once and for all to rimming or semi-killed steel grades.

A clean steel in the ladle is a prerequisite to a clean steel on the CC product, although most of the inclusions created during secondary metallurgy will have been eliminated by then, either by flotation driven by ladle stirring, coalescence or chemical modification. Curtailing furnace slag entrainment in the ladle, mainly at end of tap, and reducing whatever amount is collected there is also a prerequisite. Obtaining the final clean steel sold to the user makes it necessary to keep all the contaminations under careful control and to allow more NMI elimination in tundish and mold. A complex series of detailed technologies is available to do so, some simple add-on features (e.g. argon injection in the sliding gate or the submerged nozzle) and other hardwired features like a vertical straight-mold and curved CC for making low-carbon high-end slabs.

All of these steps and measures imply as much automatic devices and computer control as possible along with talented and very 
experienced operators following strict procedures. Mishaps and incidents, which are inevitable, should be chased relentlessly, but this will always mean that some slabs are diverted to less demanding applications and that the whole process is unlikely to ever become fully automated, like an automotive production plant can be. A continuous tracking of quality from the steel shop to the shipping of commercial steel product, resting on the collection of sensor data, real-time on-line modeling has been developed and used in the most elitist steel mills - a sort of prequel to "Big Data".

This draws a picture of a mature field, where the technology has been solidly developed and frozen into equipment and practices, which has guaranteed systematic, robust and stable quality and cleanliness, since the 1990s. Research carries on, not so much to exhibit radically new concepts, but to ensure that the level of competencies and excellence in controlling quality is maintained at the highest level. This means a continuous stream of research, updating the description of the state of art, as it changes incrementally, refining the physical understanding of physical chemical phenomena through more and more sophisticated modeling and simulations, adding more complex sensors along the production lines and integrating them into a holistic, systemic quality management system, possibly based on "Big Data" approaches.

On the other hand, clean means also clean steelmaking, i.e. making sure that the price to pay for very clean steels is not a dirty environment.

Apart from being a different discipline run mostly by teams of environmental and process engineers, clean steelmaking extends across the whole value chain, thus from the mines to the industrial manufacturing of goods and eventually to their end of life, their reuse and their recycling. Clean steelmaking is addressing a broad range of complex issues, from air/water/soil emissions to raw material and energy savings and, more generally, societal challenges like pollution, climate change or biodiversity conservation and social challenges like providing the eco- and techno-spheres with anthropospheric services and participating to the enforcement of people's well-being.

Clean steelmaking is handled by technologies, which adjust to objectives set by scientists and to quantitative targets set by regulations. Note incidentally that the level of control necessary to make clean steels helps control steelmaking in general and thus participates in keeping it clean.

The general trend is met by compliance rather than by the manic, detailed control that clean steels necessitate. Thus the numbers describing clean steelmaking are of a different nature from those describing clean steels.

The field of clean steelmaking is probably still under construction, as the ecological transition under way to meet the threats of climate change (low-carbon production) and the need to use resources more sparingly makes it necessary to look for solutions which are still to be scaled up to TRL9 for some and invented from scratch for others. There are also unsolved issues with mine tailings. This is a major difference with making clean steels.

Note also that because technology uses materials that are extracted at great energy and logistical costs from natural resources, industry creates a stream of secondary materials which needs to be handled with care and differently from the primary stream that includes steel. Very schematically, the point is to make sure that the concentration of eco- or human-toxic components in the secondary stream are diluted back into the environment to the level where the miners found them and/or treated to alleviate pollution issues, thus to revert them to a purity defined by the "natural" state in which they were found, rather than the purity as defined for a clean steel.

The holistic nature of the industrial process thus raises a diverse and complex set of issues, an explanandum ${ }^{22}$ that ought to be addressed in the future, including by defining it better. The storyline of a continuous progress does not hold any longer. Social sciences, such as anthropology, ethnology, archeology and history will probably

\footnotetext{
22 An explanandum is a set of basic, theoretical issues that a discipline should strive to tackle and eventually to explain.
} 
provide intellectual guidance to move in this direction. This connects with the endeavor of the SOVAMAT initiative [55].

The concept of purity should probably also be questioned. Steel and materials in general have seemed content in providing purity and cleanliness to manufacturing industries, which strive on complexity and on mixing of very many components into sophisticated but very "dirty" artifacts. One solution is eco-design, a lively, active and creative field.

As far as steel is concerned, purity may not be sustainable in the long term; because raw materials, primary but also secondary, will become less and less pure; because the cost of purity is more energy and because the purity may not be necessary: for example, copper, which is a poison in steel because of surface cracking during continuous casting, is no longer a problem (up to $10 \%$ [58]), if solidification takes place at higher kinetics on a strip caster! Similarly, phosphorous is now added to new high-end steel for the automotive sector for hot forming and quenching (e.g. ArcelorMittal's USIBOR [59]). Much more options are potentially feasible due to the almost infinite possibilities offered by metallurgy.

This paper is part of a continuing effort to think the activities related to steel and materials in a broader context than that of engineering sciences. It is a contribution to the SOVAMAT initiative [55] and to the work of its community presented at the Society and Materials Conferences. It is also part of the effort to propose a sustainability dimension to metallurgy and to material science [46].

\section{Acknowledgements}

Special thanks to Michel Faral, who shared his deep understanding of clean steels with me.

\section{References}

[1] J.-P. Birat, Alternative ways of making steel: retrospective and prospective, Centenaire de la Revue de Métallurgie, Paris, 9 décembre 2004, La Revue de Métallurgie-CIT, Novembre 2004, pp. 937-955

[2] P. Brun, P. Ruby, L'âge du fer en France, premières villes, premiers états celtiques, $\mathrm{La}$ Découverte, 2008, p. 177
[3] A. Testard, Avant l'histoire, l'évolution des sociétés de Lascaux à Carnac, nrf, éditions Gallimard, 2012, p. 549

[4] E. Bellevrat, P. Menanteau, Introducing carbon constraints in the Steel sector: ULCOS scenario and economic modeling, La Revue de Métallurgie-CIT, September 2009, pp. 318-324

[5] J.-P. Birat, Matériaux \& Techniques 103 (2015) 501

[6] J.-P. Birat, Metall. Res. Technol. 112 (2015) 206

[7] J. Friedel, personal communication, 1975

[8] J.-P. Birat, Ironmak. Steelmak. 28 (2001) 152158

[9] S. Ogibayashi, Advances in Technology of oxide metallurgy, Nippon Steel Technical Report, No. 61, April 1994, pp. 70-76

[10] S. Beauvais, P. Fluzin, Archeo. Sci. 30 (2006) 25-43

[11] http://www.astm.S.Oghibayashiorg/ Standards/E45.htm

[12] Y.D. Yang, A. McLean, Some metallurgical considerations pertaining to the development of steel quality, in Treatise on process metallurgy, edited by Seshadri Seetharaman, Elsevier, 2014, pp. 251-282

[13] F. Ruby-Meyer, A. Carré, E. Hénault, Optimisation of sampling at liquid steel state and correlative inclusion assessment of liquid steel for the improvement of high performance steel grades production process (SOpliqS), Contract No. RFSR-CT-2007000051 July 2007 to 30 June 2010, Final report

[14] A.D. Wilson, Clean Steel technology - fundamental to the development of high performance steels, Advances in the production and use of steel with improved internal cleanliness, ASTM STP 1361, 1999

[15] J. Pokorny, A. Pokorny, Inclusions non métalliques dans l'acier, Techniques de l'ingénieur, Référence M220, 10 juin, 1998

[16] J.P. Bellot, Maîtrise du comportement des inclusions dans les poches d'acier liquide - CIREM, ANR, 18/10/2013, http://www. agence-nationale-recherche.fr/fileadmin/ documents/2013/matetpro2013/pres/14 CIREM_Bellot.pdf

[17] A. Guinier, Personal reminiscence, in Fifty years of X-Ray diffraction, P.P. Ewald, editor, International Union Of Crystallography, July 1962, 574-578, http://www.iucr.org/_ data/assets/pdf_file/0004/769/guinier.pdf

[18] L. Zhang, B.G. Thomas, Inclusions in continuous casting of steel, XXIV National Steelmaking Symposium, Morelia, Mexico, 26-28 November, 2003, pp. 138-183

[19] J.-P. Birat, Continuous casting - history, actual situation and future prospects, ECCC 2005, 5th European Continuous Casting Conference, Nice, 20-23 June, 2005 
[20] J.-P. Birat, J.Y. Lamant, M. Larrecq, J. Pétégnief, The continuous casting mold: a basic tool for surface quality and strand productivity, Steelmaking Proceedings, 1991

[21] J.-P. Birat, C. Marchionni, Continuous Casting, Past, Present And Future. .. , ECCC 2005, 5th European Continuous Casting Conference, Nice, 20-23, June 2005

[22] J. Saleil, J. Le Coze, La propreté des aciers: une longue conquête scientifique et technologique de la sidérurgie, Matériaux $\mathcal{E}$ Techniques 103 (2015) 506, 507, 508

[23] X-ray tomography in material science, edited by J. Baruchel, J.Y. Buffiere, E. Maire, 2000; 208 p; Hermes science publications, Paris, France, 2000, 208 p.

[24] C. Gusenba, M. Reiter, J. Kastner, G. Kloesch, Detection of Non-Metallic Inclusions in Steel by X-ray Computed Tomography and After Fatigue Testing, 11th European Conference on Non-Destructive Testing (ECNDT 2014), Prague, Czech Republic, October 6-10, 2014

[25] R. Kiessling, Met. Sci. 15 (1980) 161-172

[26] L. Zhang, B.G. Thomas, Alumina inclusion behavior during steel deoxidation, 7th European Electric Steelmaking Conference, Venice, Italy, Associazione Italiana di Metallurgia, Milano, Italy, May 26-29, 2002, pp. 2.77-2.86

[27] T. Toriyama, Y. Murakami, T. Yamashita, K. Tsubota, K. Furumura, J. Iron Steel Instit. Jpn 81 (1995) 77-82

[28] H.V. Atkinson, G. Shi, Progress Mater. Sci. 48 (2003) 457-520

[29] D.C. Hilty, D.A.R. Kay, Electric Furnace Steelmak. Conference Proc. 1985, Vol. 43, p. 237

[30] Y. Murakami, S. Kodama, S. Konuma, Int. J. Fatigue 11 (1989) 291-298

[31] D. Quantin, Aciers... juste de la matière grise, SF2M 1945-2015, 70 ans de Métallurgie et de Matériaux, maison de la chimie, Paris, 20 mars, 2015

[32] ESTEP web site, Ensuring profit and innovation, http://cordis.europa.eu/estep/wg1profit-innovation_en.html , accessed on 27 July 2015

[33] J.-P. Birat, Steel Products development, EuroSteel Master 2015, VII edition, 11-15 May 2015, Terni, Matériaux \& Techniques, to be published

[34] J.-P. Birat, P. Destatte, Prospective industrielle et économie circulaire : concept élégant et réalité complexe cours-conférence au Collège Belgique, mardi 5 mai 2015, de 17 à 19 heures, Palais provincial de Namur, http://lacademie.tv/conferences/ prospective-industrielle-et-economiecirculaire

[35] Raw Materials Improvement Report, 2 April 2014, World Steel Association, ISBN : 978-2930069-72-2
[36] J.-P. Birat, M. Chiappini, C. Ryman, J. Riesbeck, Revue de Métallurgie 110 (2013) 97131

[37] B. de Lamberterie et al., ESTEP-EUROFER Steel production - energy efficiency working group, Final report, January 2014, ftp:// ftp.cordis.europa.eu/pub/estep/docs/wg7final-report.pdf

[38] J.-P. Birat, Steel sectoral report, Contribution to the UNIDO roadmap on CCS, Global Technology Roadmap for CCS in Industry sectoral workshop, Abu Dhabi, 30 June-1 July 2010; http://www.unido.org/fileadmin/ user_media/Services/Energy_and_Climate_ Change/Energy_Efficiency/CCS/Stee_ sectoral_\%20report.pdf

[39] J.-P. Birat, H. Lavelaine, Steel production \& smart electricity grids, 2014, http://cordis. europa.eu/estep/docs/steel-productionand-smart-electricity-grids-website2.pdf

[40] J.-P. Birat, J. Borlée, H. Lavelaine, P. Négro, K. Meijer, J. van der Stel, P. Sikstrom, ULCOS PROGRAM: AN UPDATE IN 2012, Scanmet IV, 10-13 June 2012, Luleå, Sweden, vol. 1, pp. 35-44

[41] Directive of the European parliament and of the council amending Directive 2003/87/EC to enhance cost-effective emission reductions and low-carbon investments, European Commission, 15 July 2015, http://ec.europa.eu/clima/policies/ets/ revision/docs/com_2015_337_en.pdf

[42] http://ec.europa.eu/clima/policies/ets/ revision/index_en.htm

[43] J.-P. Birat, Unconventional ways on which to base the value of $\mathrm{CO}_{2}, \mathrm{CO}_{2}$ Economics seminar, ESTEP, Brussels, 17 September, 2013, ftp://ftp.cordis.europa.eu/pub/estep/ docs/co2-economic-seminar-final_en.pdf

[44] Best Available Techniques (BAT) Reference Document for Iron and Steel Production, industrial Emissions Directive 2010/75/EU (Integrated Pollution Prevention and Control), 2013, http://eippcb.jrc.ec.europa. eu/reference/BREF/IS_Adopted_03_2012. pdf

[45] L. Liu, L. M. Kauri, M. Mahmud, S. Weichenthal, S. Cakmak, R. Shutt, H. You, E. Thomson, R. Vincent, P. Kumarathasan, G. Broad, R. Dales, Int. J. Hygiene Environ. Health 217 (2014) 279-286

[46] J.-P. Birat, Sci. Technol. Steelmak. 85 (2014) 1240-1256

[47] Water and Steel: Research and Technology development needs, ESTEP and WssTP, June 2013, edited by JP. Birat, 52 p., ftp:// ftp.cordis.europa.eu/pub/estep/docs/watersteel-report_en.pdf 
[48] J.-P. Birat, C. Alzamora, S. Carler, A-C Moonen, E. Malfa, Biodiversity, business and the steel sector, ESTEP working document, February 2014, 23 p.

[49] Convention on Biological Diversity, United Nations, 1992, https://www.cbd.int/doc/ legal/cbd-en.pdf

[50] J.-P. Birat, Metallurgy in Society and Scientific excellence, Invited keynote, SFI Metal Production, NTNU, Trondheim, 23 June 2015

[51] H. Lavelaine, J.P. Birat, Eco-design of steel production and induced social services, 8th International Conference on Society \& Materials, SAM-8, Liège, 20-21 May, 2014

[52] N. Stern, The Stern review: the economics of climate change, 576 pages, 2006, http://siteresources.worldbank. org/INTINDONESIA/Resources/2262711170911056314/3428109-1174614780539/ SternReviewEng.pdf, Archived from the original on 31 January 2010, Retrieved 4 August 2015
[53] The Economics of Ecosystems and Biodiversity (TEEB), An Interim Report. European Communities. 2008, 70 p. and subsequent publications, http://www.teebweb. org/our-publications/all-publications/

[54] Europe 2020 strategy, http://ec.europa.eu/ europe2020/index_en.htm and Horizon 2020's societal challenges, http://ec.europa. eu/programmes/horizon2020/en/h2020section/societal-challenges

[55] presentation of the SOVAMAT Initiative, www.sovamat.org

[56] J.-P. Birat, A. Declich, S. Belboom, G. Fick, J.-S. Thomas, M. Chiappini, Metall. Res. Technol. 112 (2015) 501

[57] J.-P. Birat, Matériaux et Techniques 103 (2015) N5

[58] J.-P. Birat, Coulée continue de bandes d'acier, Techniques de l'Ingénieur, M7816, 2000, pp. $1-20$

[59] http://automotive.arcelormittal.com/ europe/products/FR 